\title{
Exploring multiuser virtual teaching simulation as an alternative learning environment for student instructors
}

\author{
Fengfeng $\mathrm{Ke}^{1} \cdot$ Zhaihuan Dai $^{1} \cdot$ Mariya Pachman ${ }^{2} \cdot$ Xin Yuan $^{3}$
}

Received: 20 October 2020 / Accepted: 28 July 2021 / Published online: 22 August 2021

(c) The Author(s), under exclusive licence to Springer Nature B.V. 2021

\begin{abstract}
In this mixed-method study, we investigated the impact and design of a multiuser, virtual reality (VR) supported teaching simulation, in comparison with live classroom teaching simulation, on the participatory training of teaching and the teaching knowledge development of student instructors. A total of 40 university teaching assistants participated in a 4-h training session in which they were randomly assigned to a VR simulation or a live classroom simulation condition. The study indicated that the VR simulation better promoted the lab-teaching knowledge development than the live simulation, whereas the latter better fostered class-teaching knowledge development. All participants reported higher teaching self-efficacy after the training. The qualitative data indicated that domain-specific challenges and authentic environmental prompting in the VR simulation fostered both experiential and vicarious learning of teaching. However, VR participants lacked mutual engagement in collaborative role-playing. The study findings suggest that VR-based simulation can supplement and work as an alternative to the live classroom simulation to host participatory teaching development.
\end{abstract}

Keywords Training of teaching $\cdot$ Role-playing $\cdot$ Simulation · Virtual reality $\cdot$ Teaching assistants

Fengfeng Ke

fke@fsu.edu

Zhaihuan Dai

zd12@my.fsu.edu

Mariya Pachman

mariya.pachman@gmail.com

Xin Yuan

xyuan@cs.fsu.edu

1 Department of Educational Psychology and Learning Systems, Florida State University, Tallahassee, FL 32306-4453, USA

2 Distance Learning and Instructional Technology, Texas A\&M University, Kingsville, TX 78363, USA

3 Department of Computer Science, Florida State University, Tallahassee, FL 32306, USA 


\section{Introduction}

Teaching by nature is human interaction with distinct intentionality and adaptivity (Strauss et al., 2002). Understanding how an educator interacts with students in a challenging learning situation is important for understanding teaching as a social phenomenon and a practice of human development (Labaree, 2000). Teaching is also an evolved intellectual skill that develops dynamically and within context (Rodriguez, 2012). Like disciplinary expertise, knowledge of teaching is not an information object that can be simply transmitted to an educator as an empty vessel; it has to be constructed when the educator interacts with his/ her teaching context. A teaching context has multiple variables such as the learner, learning tools, and the classroom environment that dynamically interact with the teaching processes. Educators are constantly planning, experimenting, reflecting on, and adapting their actions and the control of a learning environment based on the interactions they have with their learners to produce intellectual and behavioral success (Clark \& Peterson, 1986; Hall $\&$ Smith, 2006). Due to all these contextualized uncertainties, teaching development is considered one of the most demanding professional practices (Labaree, 2000). However, most prior approaches to fostering teaching development, especially for future instructors and academics in higher education, are prescriptive, based mainly on direct instruction or demonstration for observation, and still emphasizing the knowledge transmission to the trainee as the passive recipient (Akkerlind, 2008; DeChenne et al., 2012).

There are a rising number of empirical studies and theoretical papers arguing for participatory teaching development in which the trainees should proactively and consciously engage in the experience of solving complex teaching problems, making decisions, reflecting in and upon action, and collaborating with other key actors of an educational system (Baran et al., 2011; Warhurst, 2006). Particularly, the participatory approach to teaching development emphasizes the trainees' constant and reflective practice of interacting with students in a variety of instructional situations. Only through centrality of experience and critical reflection in and upon experience (Mezirow, 2000), will novice educators appropriately validate, develop, and effectively act on different beliefs, interpretations, and ways of teaching. The process of participatory training of teaching can be structured by collaborative experiencing, participant observation, and reflection, assisted by trainers acting more as facilitators and resource personas rather than experts. Both active action and observational experience of teaching, based on the social cognitive theory (Bandura, 1994), help to promote the development of teaching self-efficacy_personal beliefs about one's capabilities to help students learn (Schunk \& Pajares, 2009; Tschannen-Moran \& Johnson, 2011). Prior research has found teaching self-efficacy a key predictor on patterns of teaching behaviors and practices related to classroom quality and factors underlying instructors' psychological well-being (DeChenne et al., 2015; Komarraju, 2008; Mills, 2011; Zee \& Koomen, 2016). As such, the process of learning to teach and of change in self-efficacy becomes as important as the product in participatory teaching development (Shaeffer, 1993).

Training by simulation, grounded in trainees' role playing as teachers and/or students given particular instructional situations and authentic problems, is a common method for participatory training of teaching (Theelen et al., 2019). Simulation, in a broad sense, refers to the imitation or representation of dynamic features and structural elements of a realworld system, entity, phenomenon, or process (Frasson \& Blanchard, 2012). Simulation can help prospective educators construct and apply teaching knowledge in a context-rich experience without the budget and time constraints or the high-stakes risk of causing harm 
to actual students (Bradley \& Kendall, 2014; Theelen et al., 2019). Simulation-based training of teaching ranges from microteaching (Allen \& Eve, 1968), video-based role playing (e.g., Koc, 2011), classroom or authentic role playing (e.g., Leaman \& Flanagan, 2013), to recently computer-based single-user simulation (e.g., Dieker et al., 2014; Badiee \& Kaufman, 2015; Bautista \& Boone, 2015) and multiuser virtual reality (VR) based simulation (e.g., Ke et al., 2020; Cheong, 2010; Dalgarno et al., 2016; Mahon et al., 2010; Quintana \& Fernandez, 2015).

It is worth to note that prior research on simulation-based training of teaching has predominantly focused on teaching development in the K-12 school setting. Despite the prevalent claim or interest in using virtual simulation as a versatile and realism- or presence-enhancing alternative to classroom simulation (Cheong, 2010; Dalgarno et al., 2016), empirical research examining the effect of using virtual simulation in comparison with classroom simulation for teaching development is still lacking. It is warranted to investigate how we can use current learning technologies to efficiently and effectively motivate and train prospective university educators to improve their teaching skills and practices.

Building on the aforesaid theoretical perspectives and prior research, the current study aimed to examine the impact of a multiuser VR-based teaching simulation, in comparison with live classroom teaching simulation, on the participatory training of teaching and the teaching knowledge development of university student instructors. Endorsing the approach of participatory simulation- 'diving into' the simulated space and directly engaging with the simulated system or phenomenon (Ackermann, 2012; Colella, 2000), the teaching simulation in this study extends and integrates the representation of variant instructional scenarios and tasks with the participatory and collaborative role playing. The study addresses the following research questions (RQs):

(1) How does the multiuser VR-based teaching simulation compare to the live teaching simulation in the impact on university student instructors' teaching knowledge and self-efficacy development?

(2) How do student instructors participate in the multiuser VR-based simulation-based training of teaching?

\section{Literature review}

\section{Simulation-based training of teaching}

Simulations are not new for the training of teaching, but they are gaining prominence as the need for concrete practice with instructor-student interactions and teaching enactment in authentic situations is emphasized (Bradley \& Kendall, 2014; Kaufman \& Ireland, 2016; Theelen et al., 2019). The Gates Foundation Measures of Effective Teaching (MET) study (Kane et al., 2014) reported that classroom practices associated with press (e.g., keeping students on task and persistent while challenging them to think rigorously) and support or instruction (e.g., caring, advising, captivating, clarifying, and consolidating) were positively associated with students' learning and engagement. These complex practices, considered the core aspects that contribute to teaching effectiveness, have typically been learned and fostered through practicum experiences (Becker et al., 2017; Grossman et al., 2009; Richards-Babb et al., 2014). However, providing an effective practicum experience is often an administrative and logistical challenge; the practicum often suffers from the 
lack of opportunities to work with diverse students or teaching situations, and the limited opportunities for repeated practice (Badiee \& Kaufman, 2015; Kaufman \& Ireland, 2016). Consequently, training of teaching in university has traditionally relied on passive observation or abstract conceptualization, such as lecture and case discussion. The need for training to bridge the gap between abstract and concrete-real experience of teaching is critical for future university instructors (DeChenne et al., 2012).

Simulations have been considered a promising way to supplementing and enhancing a concrete teaching practice in authentic situations by facilitating repeated practice with different types of students in a variety of teaching scenarios, including rare or risky ones that are ethically or logistically difficult to create in the real world (Bradley \& Kendall, 2014; Kaufman \& Ireland, 2016; Theelen et al., 2019). With simulations, trainees of teaching can make mistakes without harming actual students (Badiee \& Kaufman, 2005). Simulationbased teaching practice also supports collaborative learning along with peer observation and critique. A common way of simulating the teaching practice is scenario-based role playing — simulating realistic teaching events and confronting student instructors with realistic problems when they take on and practice teaching roles (Clapper, 2010).

\section{Role-playing simulations for training of teaching}

Computer-assisted role-playing simulations have been applied in training of teaching with growing success, but the existing research focuses predominantly on school teacher education. For example, previous studies have examined single-user, 2D or 3D online classroom simulations such as simSchool, IVT-T, and ClassSim, in which the player takes on the role of a teacher to practice classroom teaching skills by analyzing student profiles, practicing classroom management and responding to individual students, and getting feedback from the simulation on their teaching actions/choices (e.g., Badiee \& Kaufman, 2014; Deale \& Pastore, 2014; Ferry et al., 2012; Shernoff et al., 2020). It is reported that these simulations provide a valid simulated environment for pre-service teachers to practice instructional activities based on qualitative observation and participants' perceptions. A mixed-reality teaching simulation by University of Central Florida (Dieker et al., 2014), called TeachLivE, is another single-user simulation that utilizes virtual puppetry where the pre-service teacher acts by standing and speaking to a classroom of simulated students on a screen. The simulated students are puppeteered by an actor at a remote location who sees the user (via a web conferencing system) and role-plays the students' responses (via motion sensors). Bautista and Boone (2015) conducted a mixed-method study on the impact of this virtual-puppetry single-user simulation for 62 pre-service early childhood teachers. Their pre- and posttest comparative analysis indicated that pre-service teachers' science teaching self-efficacy increased significantly after one semester of using the teaching simulation. Similarly, Dawson and Lignugaris (2017) studied the usage of TeachLivE for pre-service special educators through observing their weekly performance in TeachLivE and their generalization of target skills to their own classrooms. They reported an overall improvement of teachers' teaching skills performance in both the virtual classroom and real classroom settings. All these aforementioned studies, however, focused on school teacher education. Empirical research on simulation-based training of university teaching is vastly lacking. 


\section{Virtual reality for teaching simulation}

Different from single-user simulations that have pre-programmed responses to threads of interactions between a teaching trainee and simulated students, a multiuser virtual reality (VR) allows multiple trainees to interact synchronously with each other and with simulated students in the teaching simulation. The current open-source VR technology (e.g., OpenSimulator) offers a low-cost alternative to extending teaching-practice time in the field; VR-supported teaching simulation can be realistic while being flexible and sustainable. VR simulation can also address multiple challenges that live classroom or other teaching simulations face, by (1) reducing the time and effort of the trainer to develop source scenarios and to integrate them into classroom-based practice, (2) alleviating the additional cost for hiring actors playing classroom roles (e.g., as simulated students), and (3) being open-source, sustainable, and accessible as a widely distributed platform (Kaufman \& Ireland, 2016; Theelen et al., 2019). Therefore, VR simulation can serve as an alternative or additional resource for student instructors with both real-life and virtual accesses, supplementing the live classroom simulation and other teaching education practices (Gregory \& Masters, 2012).

Recently the use and research of VR for teaching simulation is emerging (e.g., Dalgarno et al., 2016; Mason et al., 2011; Mirliss, 2014; Ke et al., 2016). For example, Dalgarno et al. (2016) studied classroom role-playing housed in SecondLife (VR) for on-campus training of first-year teacher-education-major students. The students undertook virtual classroom role-playing in subgroups over a 2-h training on classroom management and instruction. In the post-training survey, the majority of participants reported the VR-based role-playing was helpful in preparing for professional teaching practices. They highlighted the value of practicing in the role of the teacher by responding to unexpected classroom events, experiencing the activity from the perspective of the school student, and interacting with and observing their peers in the role of the teacher. However, a small number of trainees expressed reluctance to undertake simulation activities. In a qualitative observation study by Quintana and Fernández (2015), participants of the Second Life-supported teaching education reported that the experience was supportive of teaching practices in spite of perceived technical difficulty with the VR platform. Mirliss (2014) studied a VRbased classroom management simulation where trainees undertook role-playing activities with virtual students that represented learners with diverse and special needs. The study reported that the use of VR role-playing activities in undergraduate education courses, in comparison with the control group, supported the development of positive attitudes toward supporting diverse learners but not the teaching efficacy. Gregory and Masters (2012) conducted a study on using Second Life-supported VR for pre-service teachers to practice teaching. The study reported that VR-based role-playing simulation made pre-service teachers "think in complex and creative ways by assisting them in considering multiple perspectives on a topic" (p.427). Mason et al. (2011) studied a VR-based microteaching simulation in which literacy tutors delivered direct instruction to researcher-controlled student avatar. The qualitative study results suggest that effective teaching behaviors trained in a multiuser virtual environment transferred to face-to-face instruction.

Despite an increased interest in and recent qualitative evidence supporting VR-based teaching simulation, empirical research on its impact as an alternative form of training for student instructors in the higher education setting is still lacking. On the one hand, role-playing simulations that use technology to model teaching events and roles often provide flexibility and more realistic user experience of practice in clinical settings (Kaufman \& Ireland, 2016). A 
potential advantage of VR-based role-playing over live role-playing is that the former allows for visual realism and hence fosters identification with or engagement in the allocated roles and simulated classroom events, thus addressing a key limitation of conventional classroom simulations identified by prior research (Dalgarno et al., 2016; Jamaludin et al., 2009; Jarmon et al., 2009). On the other hand, trainees who are unfamiliar with the virtual world can be demotivated or distracted by the complexity of the simulation-based learning environment from training goals (Dalgarno et al., 2016).

Empirical research examining the effectiveness of computer-assisted teaching simulations in comparison with live teaching simulation is much lacking. Hummel et al. (2015) conducted a study to examine the usage of a collaborative, classroom-management simulation game in both online and face-to-face conditions. The study found non-significant difference in the learning effect between the online and the face-to-face condition, reporting that collaborative online teaching simulation can work as an alternative to live classroom simulation without decreasing learning outcomes. However, the study by Hummel et al. examined only an online choice-making game that is text-based rather than a highly-interactive role-playing simulation. It is important to further investigate the impact of the VR-based simulation in comparison with the live classroom simulation for the training of teaching, as well as the emergent participation processes of the university study instructors in the VR-based role-playing teaching simulation.

\section{Methods}

In this study we adopted an experimental, pretest-posttest control group research design and complemented it with in-situ data to examine the learning process and outcome of a VR-based simulation in comparison with the live simulation for participatory training of teaching. We conducted both quantitative and qualitative analyses with the data to examine the process and impact of simulation-based participatory teaching.

\section{Participants}

Forty university teaching assistants were recruited from the chemistry department in a public university in the United States. These participants included $22.5 \%$ females and $77.5 \%$ males, with $50 \%$ of them not having any teaching experience and $37.5 \%$ being non-native English speakers. Participants were randomly assigned to a VR-supported simulation group $(n=21)$ and a live simulation group $(n=19)$ using a simple randomization process (Suresh, 2011). Both simulation groups received 4-h training of teaching in a physically co-located setting, with the VR simulation group staying in a computer lab and the living simulation group being in a conventional chemistry classroom. The procedure of simulation-based training is described below.

\section{Simulation-based participatory training of teaching}

In this study, the training of teaching was delivered via the multiuser role-playing simulation of variant teaching scenarios and activities. Based on the literature of teaching simulation, the current simulation-based participatory training focused on concrete and context-rich experience of interpersonal teaching acts along with instant feedback, peer observation, reflection on the actions, and scaffolding. 


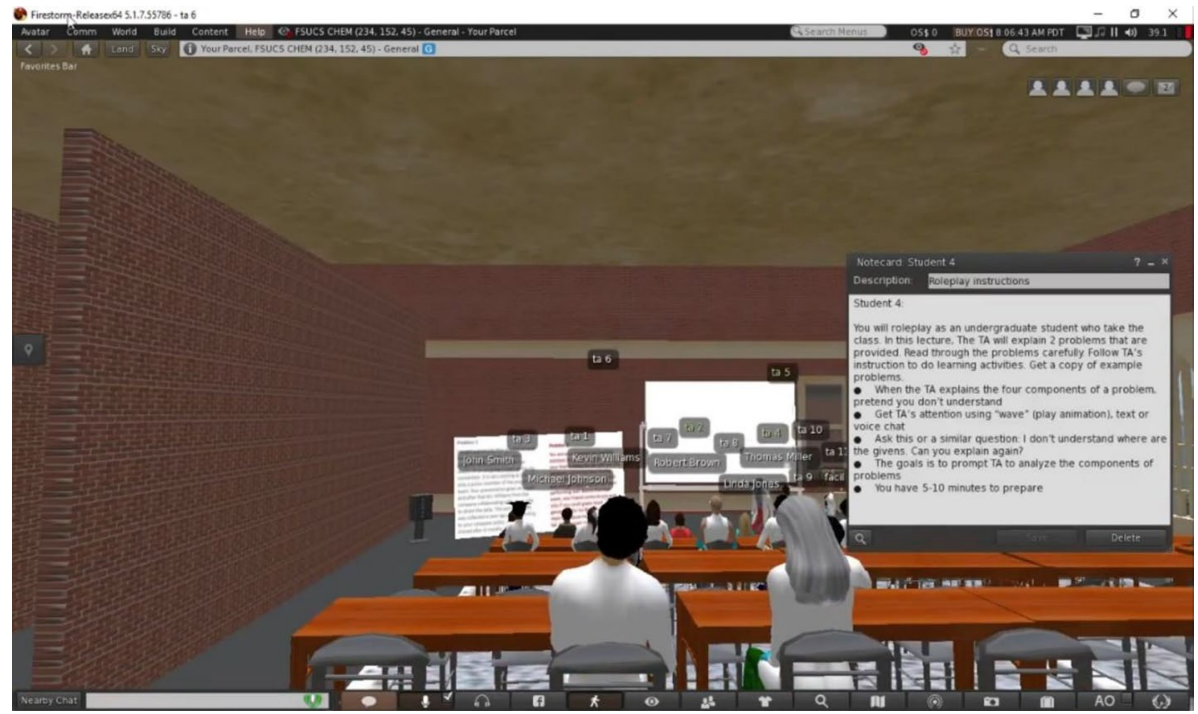

Fig. 1 Virtual Role Card at a Class-teaching Scenario

\section{VR teaching simulation}

Participants of the VR teaching simulation undertook collaborative role playing through a 3D, VR-supported simulation. Using OpenSimulator-an open-source server platform for hosting multiuser virtual reality, we constructed virtual campuses encompassing a set of simulated daily teaching scenarios or tasks, such as laboratory teaching and teaching a standard class. The virtual campuses also included a "training arena" where all participants received an orientation on VR navigation and interaction interface, and performed basic tasks (e.g., attaining a notecard, using virtual whiteboard, and interacting with scripted objects) required for the later teaching simulation. Simulation participants formed two sub-groups to interact with a same set of teaching scenarios in each virtual campus. In each sub-group the participants played and switched the roles of instructor and student during every teaching scenario, following a semi-structured protocol that outlines the backdrop mission, structure, and planned procedure of the collaborative role playing. To scaffold role-playing, each participant was requested to draw a scenario-related role card from a preset virtual dispenser at the beginning of a teaching scenario; the role card outlined a student or a teaching persona with a few brief, role-related scripts or behaviors as illustrative examples (see Fig. 1). The participants were then requested to switch roles in the midst of teaching scenario. At the end of each teaching scenario, all participants performed a reflective debriefing via the voice and text chats. Every participant in the computer lab wore headsets during the simulationbased training, and there were dividers in between the seats.

The VR-based teaching simulation, by integrating Microsoft Kinect with the OpenSimulator platform, enabled an instructor actor to project real-time gestures and body movements onto their avatar and perform embodied gesturing during virtual lecturing. A facilitator provided technical support as needed during the VR simulation-based training. In the virtual world, advisory cues and interactive prompts for reflection on 


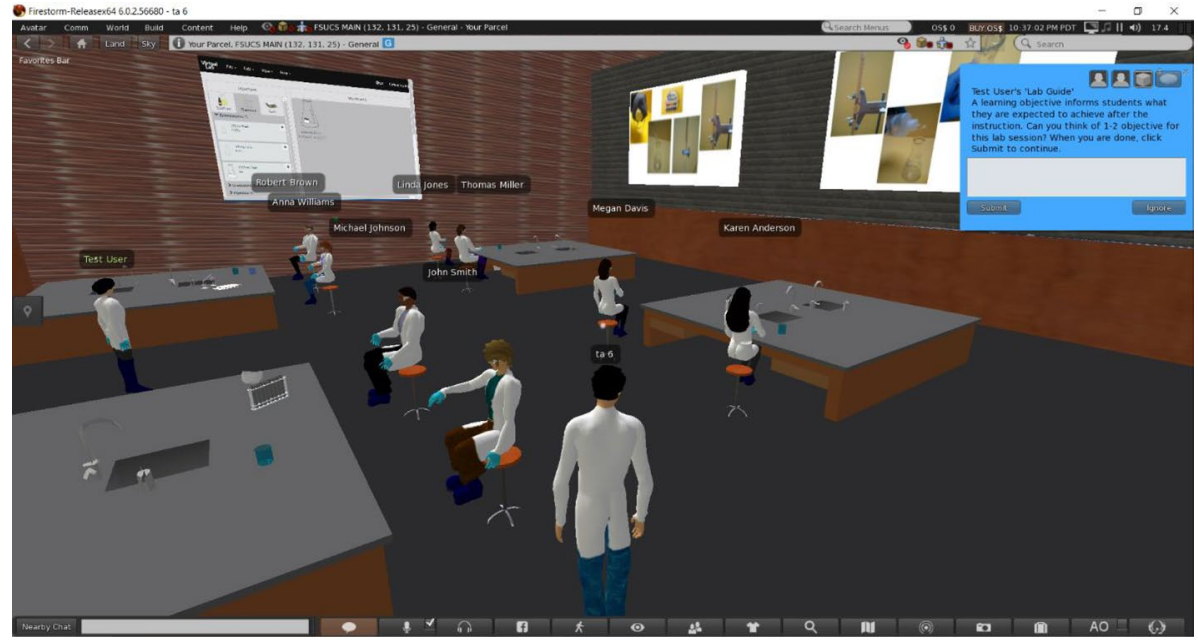

Fig. 2 Interactive Prompts in Dialogue Box at a Lab-teaching Scenario

teaching actions were presented via dialogue boxes popped-up on the screen during a teaching scenario (as Fig. 2 shows).

\section{Live teaching simulation}

Participants of the live teaching simulation performed collaborative role-playing for the simulated teaching scenarios in a typical chemistry classroom. The protocol, materials, and content of participants' role-playing and learning activities in the live simulation setting were similar to those in the VR simulation group, except that all activities were performed in person in a physical space - an actual classroom equipped with whiteboards, a projector, and a teaching station. The live teaching simulation was facilitated and coordinated by an experienced teaching-assistant trainer. The live simulation participants received paper role cards, guidance and information via the PowerPoint slides, as well as the facilitator's verbal prompts during teaching role-play.

\section{Instruments and data collection}

All participants received a teaching knowledge test and a teaching self-efficacy survey before and after the study session. The teaching knowledge test was developed based on the existing graduate teaching training materials of the chemistry department, and encompassed 12 chemistry lab-teaching story problems (Cronbach's $\alpha=0.88$ in this study) and four domain-general class-teaching story problems (Cronbach's $\alpha=0.61$ ). Each problem presented a scenario narrative and asked the participants to select all applicable problem solutions in a checklist. Each item was scored on the number of correct answers selected (see Appendix for examples). The STEM Graduate Teaching Assistant (GTA) teaching self-efficacy survey by DeChenne et al. (2012), validated in prior research on GTA teaching training, was adopted in the study. The survey consists of 15 five-point Likert scale items (Cronbach's $\alpha=0.95$ in this study). 


\begin{tabular}{|c|c|c|c|c|}
\hline Behavior & Modifiers & Behavior type & Start (s) & Scenario \\
\hline Prompting & Facilitator|Teaching stratety & POINT & $2511.245 \quad 2511.245$ & Explain3 \\
\hline ReactToPrompt & Clarify & POINT & 2544.2672544 .267 & Explain 3 \\
\hline ReactToPrompt & AttendingTolt-Satisfactory & POINT & 2594.9332594 .933 & Explain 3 \\
\hline Prompting & NPC|Teaching stratety & POINT & $2648.202 \quad 2648.202$ & Explain 3 \\
\hline Prompting & Facilitator|Teaching stratety & POINT & 2695.7332695 .733 & Explain 3 \\
\hline ReactToPrompt & AttendingTolt-Satisfactory & POINT & 2725.0452725 .045 & Explain3 \\
\hline Feedback & Instantly post|Summative|Facilitator & POINT & $2783.138 \quad 2783.138$ & Explain 3 \\
\hline Feedback & Instantly post|Summative|NPC & POINT & 2785.4002785 .400 & Explain 3 \\
\hline Prompting & NPC |Domain content & POINT & 2854.6662854 .666 & Explain 3 \\
\hline Prompting & Facilitator|Teaching stratety & POINT & 2873.5672873 .567 & Explain 3 \\
\hline ReactToPrompt & AttendingTolt-Satisfactory & POINT & 2903.1812903 .181 & Explain3 \\
\hline Feedback & Instantly post|Summative|Facilitator & POINT & $2913.312 \quad 2913.312$ & Explain 3 \\
\hline Prompting & NPC|Domain content & POINT & $2925.581 \quad 2925.581$ & Explain3 \\
\hline Prompting & Facilitator|Domain content & POINT & $2934.882 \quad 2934.882$ & Explain3 \\
\hline ReactToPrompt & AttendingTolt-Satisfactory & POINT & 2949.6412949 .641 & Explain3 \\
\hline Feedback & Instantly post|Summative|NPC & POINT & 3010.1673010 .167 & Explain3 \\
\hline Prompting & NPC|Domain content & POINT & 3021.877 '3021.877 & Explain 3 \\
\hline ReactToPrompt & AttendingTolt-Satisfactory & POINT & 3050.1453050 .145 & Explain3 \\
\hline Feedback & Instantly post|Summative|NPC & POINT & 3095.242 3095.242 & Explain3 \\
\hline Feedback & Delayed post|Summative|NPC & POINT & 3102.9663102 .966 & Explain3 \\
\hline DirectInstruction & Debriefing & POINT & 3136.310 3136.310 & Explain3 \\
\hline
\end{tabular}

Fig. 3 Example of Coding with Participation Behaviors

Participants' learning interactions in the two teaching simulation settings were screen recorded and/or onsite observed. A semi-structured group interview was conducted at the end of the training with each study group, focusing on exploring participants' perceptions of their learning experiences.

\section{Data analyses}

We conducted one-way Analysis of Covariance (ANCOVA) tests to determine whether there was a statistically significant difference between the two modes of participatory simulation on participants' lab- and class-teaching knowledge as well as self-efficacy development, controlling for the pre-training teaching knowledge and self-efficacy measures. The homogeneity of variance for the ANCOVA analyses were tested and confirmed $(p>0.10)$ before the analyses.

Moreover, we conducted a qualitative thematic analysis with the training recording, observation notes, and interview responses to delineate themes that depict salient patterns governing the processes of participatory training in the VR-based teaching simulation. The thematic analysis followed the multi-phase approach proposed by Braun and Clarke (2006), including data transcription, initial open coding, themes searching and reviewing, themes consolidation and clarification, and analysis report production. Peer debriefing, or analytical triangulation consisting of recurrent formal reviews of data among the researchers, was part of the data triangulation and analysis process. The analysis contributed a set of thematic events and states depicting the core participation behaviors in VR simulationbased training of teaching (see Fig. 3 for an example). We then systematically coded the screen-captured participation behaviors using these delineated thematic events and states via BORIS, an event- or behavior-logging software. Three trained coders coded all VR simulation participants' data, with the interrater reliability being 0.94 and all discrepancies then discussed and resolved. The frequency and percentage of the salient VR-supported 
participatory training behaviors were calculated after systematic behavior coding. These qualitative and descriptive findings provided both corroboration and explanation for the unique attributes of the multiuser VR-based teaching simulation in relation to participants' simulation-based learning processes.

\section{Findings}

\section{RQ1: impact of simulation modes on teaching knowledge}

A one-way ANCOVA was conducted to examine the impact of simulation modes (the VRbased versus the live teaching simulation) on the post-training lab-teaching knowledge test scores of participants, with the participants' pre-training scores as the co-variate. The results indicated a clear tendency to significance with a medium effect size of the simulation modes on the lab teaching scores, $F\left(1,33^{1}\right)=3.48, p=0.07$, partial $\eta^{2}=0.10$. The VRsupported participatory simulation group $\left(M_{\mathrm{v}}=28.80\right.$ out of $\left.44, S E_{\mathrm{v}}=5.38, n=20\right)$ scored higher than the live participatory simulation group $\left(M_{1}=24.63, S E_{1}=6.14, n=16\right)$.

The one-way ANCOVA on the impact of simulation modes on the post-training classteaching knowledge test scores of the participants indicated a significant result, $F(1$, $37)=23.54, p<0.001$, partial $\eta^{2}=0.39$. Specifically, the live participatory simulation group $\left(M_{1}=7.47\right.$ out of $\left.17, S E_{1}=1.65, n=19\right)$ scored higher than the VR-supported participatory simulation group $\left(M_{\mathrm{v}}=5.81, S E_{\mathrm{v}}=2.20, n=21\right)$ in the post-training class-teaching knowledge test.

\section{RQ1: impact of simulation modes on teaching self-efficacy}

Another one-way ANCOVA was conducted to examine the impact of simulation modes (VR versus live) on the post-training teaching self-efficacy scores of the participants, with their pre-training self-efficacy scores as the co-variate. The result was not significant, $F(1$, $34)=0.15, p=0.71$. There was no significant impact of the simulation modes on the participants' teaching self-efficacy development. Actually, there was a general increase in the self-reported teaching self-efficacy scores of the study participants from the pre-training $\left(M_{\text {pre }}=63.24\right.$ out of a total of $\left.75, S D_{\text {pre }}=7.73\right)$ to the post-training survey response $\left(M_{\text {post }}=65.03, S D_{\text {post }}=8.21\right)$. The pairwise t-test examining the study participants' teaching self-efficacy scores before and after the training indicated a significant improvement, $t(36)=-2.76, p<0.01, d=-0.31$.

\section{RQ2: themes or patterns of VR teaching simulation participation}

We found that joint participation in prompted or improvised role-playing in the VR simulation inspired both experiential and vicarious learning of teaching-related problem solving. However, mutual engagement in role-playing didn't consistently ensue from every simulated teaching task, creating different clusters of learners on the continuum between peripheral and central participation in simulation-based teaching interactions. Approximately

${ }^{1}$ Attrition occurred when four participants did not complete the lab-teaching knowledge test. 
$55 \%$ of VR participants were more involved in vicarious learning or acquiring modelbased knowledge-observing role-playing or attending to explicit instructions presented by the VR information objects or a facilitator-than seeking to construct experience-based knowledge via acting out teaching scenarios.

In spite of heterogeneity in learners' role-playing participation, environmentally cued teaching rehearsal with multiple approaches of instructor-student interaction and dynamic class management was frequently found in participants' behaviors and dialogues during the VR teaching simulation. Active participation in role-playing was positively associated with active reflection and refinement on a teaching action. Nevertheless, some GTA participants expressed a lack of motive towards acquiring domain-general pedagogical knowledge.

Salient features of the VR simulation that either escalated or hindered participants' construction of a shared enterprise of teaching have emerged from the qualitative thematic analysis. Collectively these ergonomic design features indicated that the simulated teaching tasks, tools, and environmental prompts had to be coordinated with the motives, competencies, and limitations of the participants when they interacted with the system and other players in the simulation.

The aforementioned qualitative themes compose an in-situ description and explanation on the process and outcome of simulation-based participatory training of teaching in relation to the VR environmental conditions or constraints. These findings, supported by the participants' quotes and observed behaviors, are presented below.

\section{Theme 1: peripheral to central participation}

Despite the presence of role cards and tips for role-playing, not all GTA participants actively took on or acted out a designated role during a VR-based teaching scenario. They appeared to experience a period of incubation for collaborative role-playing. At the beginning of a scenario, they tended to be watching and waiting rather than ushering in an event or a dialogue; their responses to an initiation or prompt from a peer actor were typically delayed and brief. Certain VR simulation participants were found quietly switching their role cards during role-playing. Consequently, breakdown or lengthened silence in a roleplaying conversation was frequently observed during the initial teaching scenario. Instead, all participants were found actively interacting with the VR information objects or teaching aids (e.g., posters, media boards, whiteboards, and notecards) situated in the simulation.

With the training session going on, self-formed role-playing partnership and individuals' task participation profiles emerged in the virtual collaborative learning space. The thematic and behavior analyses indicated four clusters of participation patterns: proactive performer, prompted partner, reflective observer, and onlooker (or peripheral participant). Proactive performers were characterized by the acts of self-initiating and leading roleplaying interactions, attending to task-related environmental conditions, and persevering with the task completion. In comparison, prompted partners lacked leadership or initiative but were frequently collaborators who responded to the prompting or initiation of the peers during role-playing, and/or assisted them in managing or delivering a teaching rehearsal. These two types of participants demonstrated peer coalition and mutual engagement in simulation-based participatory training. Differently, reflective observer appeared unaccustomed to collaborative role-playing. They resorted to only observing the peers' interactions, processing the teaching aids presented in the virtual world, and responding to the prompts for reflection or debriefing. They were comfortable being the passive receivers of the teaching knowledge modeled by others, but failed to collaboratively construct a shared 
enterprise of teaching. Onlookers, regrettably, lacked either mutual or solitary engagement with the designated training activities. As self-reported and observed, they experienced a learning curve with the simulation-based participatory training process, trying to make sense of the environment and task of the collaborative VR teaching simulation. The percentages of the four participation patterns varied across the simulated teaching scenarios or tasks, with $10 \%$ being proactive performers, $35 \%$ being prompted partners, $35 \%$ being reflective observer, and $20 \%$ being onlookers.

\section{Theme 2: environmentally cued teaching rehearsal}

During the VR teaching simulation, participants were found proactively refining their teaching actions based upon peers' real-time feedback conveyed in the form of either direct "student" responses or observatory comments. They also got opportunities to take on dynamic challenges emerging from a virtual lab/class and then practice multiple approaches of instructor-student interactions. On the other hand, the lack of joint attention and equivalent task engagement was frequently observed with the VR-simulation participants, possibly due to the co-presence of communal and discrete spaces and a low level of social visibility in the virtual world. These participants appeared to prioritize content over pedagogical knowledge during simulation-based training of teaching. These emerged patterns depict the nature of the emergent learner activities and knowledge construction in the simulation-based micro-community of practice, and are illustrated with examples as follows.

\section{Real-time critique and refinement of teaching actions}

VR-simulation participants were found actively contributing outspoken critiques to the ongoing teaching actions during role-playing. It appeared that the avatar embodiment in the virtual space made participants forthright with their commenting, which sometimes created confrontation as the following observation notes demonstrated.

A "student" raised another question and asked if the knowledge learned is applied to the real world. "Instructor" told him that taking the class was mainly for getting the required credits. An argument then arose between the "student" and the "instructor". The "student" continued, "If you did not wish us to know, why do I ask more questions?" The "instructor" responded, "I mean you don't have to. You can leave." The "student" instantly commented as a peer, "This is rude, very rude." Another trainee concurred, "Yeh, it is." Others tried to ease the tension. The "student" softened his tone, explaining that he felt an instruction should be presented in a personally meaningful way, with which the "instructor" agreed.

An "instructor" did not answer a "student's" question but directed her to check the textbook's answer keys. The student murmured a complaint with the voice-chat muted, then turned on the voice-chat and said, "Try not to be so aggressive. I just wanted to learn." An observing trainee supported her with a similar comment, "You are making it very difficult for us to ask questions. That's very aggressive." The "instructor" was silent for some time. At the end of this microteaching task, he made a sarcastic comment about himself, "I may get fired (as a GTA)." The previous "student" tried to comfort and reassure him, "You still provided some assistance to me." 
In the above examples, the trainees in a VR-based teaching rehearsal shifted between their virtual- and real-world identities when confronting a peer GTA with either peer critiques or student perspectives on a teaching action. These confrontations might create temporary tension during participatory training, but prompted student instructors to intently reflect upon their take-for-granted teaching actions.

VR-simulation participants were also found actively leveraging interactive lecture tools situated in the virtual world during role-playing. The VR media board that embedded interactive science simulations were frequently used by the participants for a lab introduction or an experiment demonstration during lab teaching, while the virtual whiteboard and posters on the subject matter typically accompanied the conceptual explanation or questionanswering during class teaching. When using these virtual lecture tools, "instructors" were found frequently adjusting their visual presentation or verbal explanation of a content topic. Their "students" were then actively inspecting and co-maneuvering the interactive media board and whiteboard (e.g., by typing answers or drawing equations on the board) to share perspectives on the subject matter taught. The shared maneuvering and inspection of the VR-based lectures provided VR-simulation participants a unique and an alternative avenue of sharing or acquiring real-time critique and adaptation of their teaching practices.

\section{Tackling emerged and environmentally-cued instructional challenges}

Notably, VR-simulation participants managed to present and tackle diverse instructional challenges via impromptu play that was based off the role cards and avatar embodiment as well as arranged or emergent environmental cues. As observed, participants who acted out the suggested student persona challenged their "instructors" via diverse inquiries that reflected their authentic experiences and were domain-specific. They challenged the "instructors" on both pedagogical knowledge and subject matter grasp.

A "student" interrupted the lecture of an "instructor" by requesting to leave the class early to pick up his child from school; the instructor pondered for a moment before replying. When several other inquires about an assignment were thrown out, the instructor told students to gather before the virtual whiteboard with which he then provided an item-by-item explanation of the assignment. When a frustrated "student" interrupted his presentation, the "instructor" tried to calm the student down, told him to wait for his turn, and resumed the explanation. Yet other students interjected questions here and there, with one asking whether those assignment items would show on the exam. The "instructor" handled the chaotic situation calmly and responded, "I don't know, because I am not the one who writes the exam." An observing peer commented instantly by text chat, "Oh, that's a good one (response)."

A lab "instructor" was trying to respond to an inquiry about unexpected color on the $\mathrm{pH}$ test strip paper in a titration ("My paper turned into a red color"). He shifted to a zoom-in first-person view in the virtual world, and acted like he was checking on the indicator strip to interpret the color. The "student" portrayed anxiety and asked, "Can I call you after class? Can I get your number in case I have further questions?" The "instructor" responded in a professional way, telling the student that he could email or use Google Voice as long as the inquiry was work related. He then went to check on other students, "How are you doing? ... Let me know if you have any questions."

As portrayed by the above examples, variant chaotic and demanding instructional situations, integrating the tasks of content instruction or mentoring, class management, and 
working with difficult students, were replicated impromptuly in the VR-based teaching simulation. These instructional challenges had put the participants' pedagogical and content knowledge into action and the test.

Such an impromptu simulation of instructional challenges appeared to be stimulated by emergent or pre-arranged environmental cues in the 3D virtual world. For example, a participant was editing his avatar and accidentally put on an inappropriate outfit (shorts inside a lab gown). His peers laughed, and this incident evolved into the role-play and discussion on the dressing code in the lab. In other cases, the participants were found referring to the situated cues (e.g., the pop-up virtual notecards and dialogue windows) during role-playing. They were found frequently maneuvering and consulting these pre-arranged environmental cues on a corner of the screen when participating in the teaching role-play, as the following observation notes illustrated.

TA 18 displayed multiple virtual notecards on the screen, including one on the lab introduction and one on how to scaffold scientific inquiry. He kept them open during the teaching rehearsal. Following the notecard-situated cues, TA 18 tried to dismiss content-irrelevant questions from students and managed to maintain a good pacing with the lab introduction process. When a "grade-driven" student requested him to give more details on the solution (e.g., a specific equation), TA 18 consulted the inquiry-scaffolding cues in the notecard, declined to give an exact answer, and tried to explain an analogous problem.

TA 8 carefully read the pop-up notecards on the heuristics of lab facilitation and emergency management before the lab simulation. When facilitating the lab, the fire alarm rang in the virtual classroom. He instantly asked students to get out and walked after them, "Please, everyone, leave the room. Let's go. Student 1, are you OK? Do you need CPR?" His behaviors were well aligned with what the notecard suggested about the emergency management.

The aforementioned observation notes suggest that the pre-set, scenario-related, and environment-situated cues scaffolded the performance of instructor role-play in a challenging teaching scenario.

\section{Discrete task communication and learning spaces}

The VR-supported learning space supported multiple modes of instructor-student interactions-voice and text chats as well as virtual whiteboard-enabled verbal or visual messaging. Despite the facilitator's suggestion on using voice chat, the VR-simulation participants chose to use variant preferred communication channels. Specifically, peripheral or non-native English speaking participants would communicate via a less visible approach (e.g., text chat or anonymous whiteboard typing/sketching). Their text messages, however, could be ignored by their peers who were already multitasking during role-playing. Others used text chat for sideline or private interactions. For example, two "students" were found exchanging opinions on a debatable response of the "instructor" using private chat when the latter was responding to another student inquiry. The sideline chat was sometimes shared publically by accidence, composing a distraction for the "instructor" who had to stop a verbal instruction to retrieve and process the sideline dialogue. Such type of discrete task communications were frequently observed during the VR-based teaching simulation.

We also observed the presence of discrete individual spaces beyond a communal learning space in the virtual world. Despite their virtual co-presence in a teaching scenario, VR 
participants were found occupied with their own virtual learning activities, such as rereading the environmental cues or exploring an interactive media board, rather than attending to the collaborative and ongoing role-playing task. The presence of these discrete, individualistic learning activities in the virtual world reduced the participants' joint task engagement. The social visibility of individuals in the VR group was low due to the shelter of virtual avatar and the possibility of segmenting one's actual involvement (e.g., exploring environmental objects) from his/her avatar's action (e.g., attending to an instructional event). Participating in collaborative role-playing became more self-regulated than groupregulated. Reduced joint task engagement was a frequent comment from the VR-simulation participants who complained that certain peers kept silent, appeared detached, or frequently requested information reiteration during role playing.

\section{Prioritizing content over pedagogical knowledge}

Content-related environmental setup in the virtual world, such as scientific simulations delivered via the virtual media board as well as assignment handouts shared via interactive posters in the virtual classroom, appeared to foster participants' engagement in the content-based teaching practice. Multiple participants discussed alternative approaches of explaining chemistry concepts during the debriefing activity and their group chats. A frequently-reported insight gained from the VR-based teaching simulation was on how an instructor should explain a concept via alternative representations, such as "plain English," "metaphors," and "more daily-life examples."

A tendency to prioritize content over pedagogical knowledge was observed in the participants' involvement in the simulated teaching tasks. They portrayed a higher level of task engagement with domain-specific teaching scenarios, such as facilitating a lab class and mentoring students on assignment items, than domain-generic ones, such as scaffolding generic problem analysis in a class teaching task. A few participants questioned the facilitator on the purpose of practicing the teaching of generic problem solving, "What skills do you want us to develop here?" These participants, when interviewed, admitted that they were interested in being a better GTA rather than a future instructor or professor. Teaching, according to them, was an insignificant part of graduate education or their future career.

\section{Theme 3: ergonomic learner-simulation interactions}

Along with the observations on the VR's fluid communication/learning spaces and a tendency for the participants to prioritize content expertise, the following patterns depicting ergonomic or augmented learner-simulation interactions in the VR teaching simulation have emerged: (a) domain-specific teaching challenges and environmental prompts reinforced participatory simulation; (b) explicated task structure and personal relevance reinforced collaborative role-playing; and (c) collaborative leadership fostered peers' opt-in.

\section{Domain-specific teaching challenges and environmental prompts}

Across the simulated teaching scenarios, VR participants showed a higher level of participation in collaborative role-playing with the scenarios that feature domain-specific teaching challenges (e.g., chemistry lab teaching and assignment mentoring) than the ones on domain-general teaching practices (e.g., class management), with their average participation rates being $76 \%$ and $38 \%$ respectively. As observed, participants who were typically an 
observer or even onlooker in other teaching scenarios became attentive and started to play their roles actively when chemistry-relevant environmental prompts were presented. The following observation note exemplified this pattern.

In the Lab scenario, all participants were found interacting with the media board to explore the chemical experiment simulator. TA 14, usually an observer, acted out his student role by asking questions about the $\mathrm{pH}$ paper color. TAs 5 and 6 , who were "in and out" and not engaged in the previous tasks, became attentive and responsive to the content-based instructional events in the assignment tutoring scenario. When the "instructor" presented a chemical compound on the virtual whiteboard and questioned the students on the name of the compound, TAs 5 and 6 zoomed-in on the whiteboard to read the content. TA 6 had her avatar raise a hand and asked, "I don't understand why there is a problem." Other trainees who used to be onlookers (e.g., TAs 9, 11, 21) also played their instructor and student roles actively with domainspecific teaching tasks; their avatars gathered before the interactive lecture tools during these tasks.

As illustrated above, domain-specific teaching challenges and content-based environmental prompts were associated with the portrayal of task engagement and active role-playing.

\section{Explicating task structure and relevance in collaborative role-playing}

Despite the presence of environmental prompts, VR participants reported a need of scaffold on how to proceed with virtual teaching practices. They were puzzled about when to switch communication channels or interactive lecture tools during a teaching event, and how to get a virtual class's attention and attend to it without direct eye contact or facial expression monitoring. Performing these routine teaching acts in a virtual world has a learning curve.

An explicated protocol or formulation of the task structure was found helping VR participants overcome the learning curve and stimulating their autonomy in participatory simulation. The facilitator of the VR simulation was frequently requested to explicate the task structure with a simulated teaching scenario. When the training session proceeded, participants were found generally developing and endorsing a similar activity routine: reading the activity instruction (presented by a virtual poster placed on the classroom or lab entrance), obtaining a role card from a virtual dispenser (in the form of a mailbox), processing the character profile, and then initiating or gradually joining collaborative role-playing.

Apart from explicating the task structure, customizing a simulated teaching scenario to increase its perceived relevance appeared to increase participants' role-playing engagement. For example, multiple trainees questioned the meaningfulness of a scenario featuring generic problem analysis, "What are we going to learn from this (scenario)?" They failed to associate this teaching task with their daily GTA work, demonstrating a lack of enthusiasm with this domain-general pedagogical skill. Leveraging the fluidity of VR, the facilitator rapidly updated the teaching simulation by adding participant-relevant lecture aids, including a problem-analysis example on how first-year international students made arrangements for living on or off-campus. As observed, there was an instant increase in the VR participants' verbal or text-chat contribution to this teaching task. Almost all international GTAs, who were typically reflective observers, participated in the teaching rehearsal.

Collaborative Leadership for Peers' Opt-in: Related to the need to facilitate equivalent participation in collaborative role-playing is the observation that co-leadership by pairs of 
active participants fostered peers' opt-in and the emergence of collective action. Pairing participants as co-leaders of simulated teaching occurred in consequence of the role-play (of an Instructor and an Assistant Instructor). The following example illustrated the process of collaborative leadership.

TAs 13 and 18 jointly led the virtual lab teaching. They took turns and supplemented each other in explaining the target concepts, and managing the situation when learners got sidetracked or when they appeared to be off-task (e.g., "Are you sleeping?"). They divided labor in addressing students' inquiries during the lab management: TA 13 addressed the questions of the students who failed to follow the experiment procedure while TA 18 handled the questions about $\mathrm{pH}$ test strip. TA 13 walked around monitoring lab and checking on the lab security when TA18 continued addressing students' questions. Their "students" all actively interacted with them, making the participatory simulation of teaching proceed smoothly. TA11, an observer during the previous teaching scenarios, also spoke up and joined the group in role-playing.

The above example was also observed among other paired teaching rehearsals. It suggested that partnership in co-leading a teaching simulation enabled trainees to augment each other during teaching practices, and increased the followership and the tendency for individuals to role-play collectively as a group.

\section{Discussion and conclusion}

\section{Differential impacts on knowledge of teaching}

In this study, we examined the implementation of the VR-based collaborative role-playing simulation as an alternative to the live classroom simulation for the training of teaching. The current study findings suggest that the two types of teaching simulation differed in their impact on two types of knowledge of teaching. Specifically, the VR teaching simulation tended to have an advantage in the development of domain-specific lab-teaching knowledge, whereas the live classroom simulation better promoted the development of domain-general class-teaching knowledge.

\section{Comparable impact on teaching self-efficacy}

The study also indicates that the VR teaching simulation is comparable with the live classroom simulation in supporting the teaching self-efficacy development. This finding aligns with the report of prior research on the positive role of simulation-based teaching training on teaching self-efficacy development (e.g., Bautista \& Boone, 2015). It partially supports the finding of Hummel et al. (2015) that there is non-significant difference in the learning effect between the online and face-to-face collaborative teaching simulation. An interpretation is that VR-based teaching simulations can act as an alternative to live classroom simulation in promoting teaching self-efficacy of student instructors. 


\section{Emergent learner interactions with VR-based teaching simulation}

A qualitative observation is that VR-simulation participants lack joint attention or mutual task engagement with collaborative role-playing. Potentially the open-endedness and distributed communication/learning spaces in the virtual world, as well as the nonalignment between learners' involvement and their avatars' actions, hindered the joint task engagement. Such an observation supports the report of Dalgarno et al. (2016) that learners could be distracted by the complexity of the computer simulation-based learning environment from the learning goal, and some of them were reluctant to undertake simulation activities regardless. On the other hand, the fluid environmental prompts, interactive lecture tools, and multiple information objects available in the VR teaching simulation were found to support a dynamic simulation of domain-specific teaching challenges, and foster participants' engagement in content-related teaching practices. This finding is consistent with the report of prior research on the general positive perception of VR-based teaching training experience (Gregory \& Masters, 2012; Mason et al., 2011; Mirliss, 2014; Quintana \& Fernández, 2015). Overall, VR-based teaching simulation can act as a supplement for the live classroom simulation, especially during the training of domain-specific and contentrelated teaching skills.

Nevertheless, the qualitative findings suggest that the current VR teaching simulation still fails to address GTAs' predispositions towards teaching, such as a tendency to prioritize content expertise over domain-general pedagogical knowledge, and the perception of teaching as an unessential part of professional development. This observation reflects a common attitude towards teaching-related professional development in higher educationteaching is considered a dispensable competency in comparison with research skills and content expertise (Feldon et al., 2011). To facilitate the teaching-attitude change of GTAs, we should consider augmenting the current embedded interactive prompts for self-reflection on teaching actions in the simulation, with a post-simulation, expert GTA-facilitated debriefing focusing on the practice of pedagogical content knowledge in higher education-relating one's pedagogical knowledge and teacher identity to his/her subject matter knowledge and professional identity.

\section{Implications for simulation-based training of teaching}

The study findings suggest that not all trainees actively participate in simulation-based collaborative role-playing to acquire knowledge of teaching. Given a self-regulation-contingent, artifact-abundant learning environment, individuals who differ in preferred (e.g., vicarious or experiential) learning manners and motives towards teaching tend to engage with discrete artifacts or conducts for teaching development, thus lacking joint task engagement. The findings support the learning network perspective by Goodyear et al. (2016) that learning activities are emergent processes pending how learners interact with the designed learning environment elements that are designed to resource and guide the activities.

The design heuristics found to escalate and synchronize individuals' effort for collaborative and participatory training of teaching need to accommodate their interests, competencies, and limits in interacting with a multiuser simulation system. They entail (a) personal relevance-scenarios and environmental prompts that leverage trainees' aspirations and life experiences, (b) healthy boundary—a structured communal learning space and participation protocol, and (c) recognition of both collaborative leadership and individuals' social visibility. Supporting the arguments of prior research on participatory simulation-based 
training of teaching (Badiee \& Kaufman, 2005; Dieker et al., 2014), the current study suggests the following features for designing and implementing a VR-based teaching simulation: environmentally cued teaching problems, diverse simulated students for a trainee to interact with, immediate performance feedback for reflection, domain-specific teaching tools, and cyclical procedures in teaching rehearsal with alternative perspective taking (e.g., of instructors and students).

In this study, trainees' participation behaviors in a teaching simulation appear to well reflect their actual tactics, experiences, and perceptions of teaching. This observation moderately supports the report of prior research that teaching behaviors in a multiuser virtual environment are generalizable to actual instruction (Dawson \& Lignugaris, 2017; Mason et al., 2011). As such, practicing with a teaching simulation can work not only as a learning approach but also as a diagnostic assessment tool. For example, it could help to externalize and capture one's misconception or ignorance with teaching, and present learner-adaptive activities to promote attitudes change in addition to knowledge development.

\section{Conclusion, limitations, and future research}

Adopting the perspective of participatory teaching development, we have studied a VR simulation that presents variant teaching contexts with which student instructors will interact to rehearse complex teaching practices and construct knowledge of teaching. The study findings suggest that VR-based simulation can supplement or work as an alternative to the live classroom simulation to host participatory teaching development, especially when domain-specific teaching tasks are involved, and the tasks and environment are designed to escalate and synchronize individuals' participation in simulation-based learning of teaching.

In the current study, simulation-based training of teaching took place in a 4-h training session, and may have failed to capture the longitudinal impact and process of VR and live classroom simulation-based teaching practice. The VR simulation participants were all seated in the same physical space, with their real-life identity and physical surrounding potentially distracting them from virtual role-play. A future study should further examine the process and outcome of simulation-based teaching training in a longitudinal program. Implementing VR-based teaching simulation remotely for individual participants at their convenience should be aligned with VR's fluidity nature and warrants further investigation. It is worth to note that training of virtual teaching is not only a method but also a goal itself, especially when online education is currently becoming a widespread adoption due to the COVID-19 pandemic. An investigation on how a VR-based teaching simulation can be designed and used to promote the development of online teaching or virtual lab facilitation skills is warranted. It is also important to conduct future research on cognitive ergonomics in designing a simulation-based teaching and learning environment in general. 


\section{Appendix: examples of teaching knowledge test items}

\section{Example 1: lab teaching story problem in the teaching knowledge test}

A student is rushing to finish their chemistry lab. He accidentally spills some acid on the desk, and decides to clean it up with a paper towel before leaving. In the next class a student sits down at the desk and starts to have a reaction to the acid.

\section{How this scenario could have been prevented (precautions)?}

Select answers that apply:

A. Disinfect all the lab tables before the lab.

B. Enforce the importance of washing and putting away all lab equipment before students leave the lab.

C. Don't leave students in the laboratory alone.

D. Ensure that students report anything that require a clean up to you and that they mention it to their neighbours before leaving the area.

E. Ensure that students know to use a basic solution to neutralize the acid in this and similar cases.

F. Ensure that students don't try to clean acid spills themselves.

\section{How we should respond to minimize the harm?}

Select answers that apply:
A. Call 911
B. Push the lab alarm
C. Help student to wash his hands and arm with the water
D. Proceed according to the lab safety guidelines.
E. Disinfect all the lab tables.
F. Send affected student to immediately seek medical help.
G. Send student to the safety shower.

Please, explain your response or your choice. If several choices can be applied-make sure you mention and explain them.

\section{Example 2: class-teaching story problem in the teaching knowledge test}

"The sound of silence"

Monday morning, 10am, 20 students at their desks in a small classroom

GTA: Hi everyone-I hope you had a nice weekend! How did the reading go?

Class: Vague murmurs

GTA, undaunted: I know stoichiometry can be pretty confusing! Can someone explain types of chemical reactions in your own words?

Class: Silence, students looking down

GTA: So how to balance redox reactions? 
[time passes]

What about this line here on page two, “...”?

Class: Starting to fidget...

\section{How would you navigate and manage the following teaching moment?}

Select answers that apply:

A. Make the class read lines from stoichiometry textbook, line by line and assign an additional homework.

B. Call a random student name from the roster.

C. Continue with the next lecture topic and give students more (less) homework for the next time

D. Try to quickly repeat parts of the previous lecture and proceed with the new material.

E. Put students in groups to go through the redox reactions on their own and then ask the questions again. Give them more homework after that.

F. Mention to students that some of the questions you are asking will be on mid-term and see if they are able to answer.

Please, explain your response or your choice. If several choices can be applied-make sure you mention and explain them.

\section{Examples of Interview Questions}

- How do you perceive your experience with this training session/program?

- What did you do? If given another chance, what would you do differently in this session?

- What did you observe? What did you learn?

- What would you change if you were the designer of this teaching training session/program?

Acknowledgements This work was supported by the National Science Foundation, grant 1632965 . Any opinions, findings, and conclusions or recommendations expressed in these materials are those of the authors and do not necessarily reflect the views of the National Science Foundation.

\section{References}

Ackermann, E. (2012). Perspective-taking and object construction: Two keys to learning. In Y. B. Kafai \& M. Resnick (Eds.), Constructionism in practice (pp. 39-50). Routledge.

Åkerlind, G. S. (2008). A phenomenographic approach to developing academics' understanding of the nature of teaching and learning. Teaching in Higher Education, 13(6), 633-644.

Allen, D. W., \& Eve, A. W. (1968). Microteaching. Theory into Practice, 7(5), 181-185.

Bandura, A. (1994). Self-efficacy. In V. S. Ramachaudran (Ed.), Encyclopedia of human behavior (Vol. 4, pp. 71-81). AcademicPress.

Baran, E., Correia, A. P., \& Thompson, A. (2011). Transforming online teaching practice: Critical analysis of the literature on the roles and competencies of online teachers. Distance Education, 32(3), 421-439. 
Bautista, N. U., \& Boone, W. J. (2015). Exploring the impact of TeachMETM lab virtual classroom teaching simulation on early childhood education majors' self-efficacy beliefs. Journal of Science Teacher Education, 26(3), 237-262.

Becker, E. A., Easlon, E. J., Potter, S. C., Guzman-Alvarez, A., Spear, J. M., Facciotti, M. T., Igo, M. M., Singer, M., \& Pagliarulo, C. (2017). The effects of practice-based training on graduate teaching assistants' classroom practices. CBE: Life Sciences Education. https://doi.org/10.1187/cbe.16-05-0162

Bradley, E. G., \& Kendall, B. (2014). A review of computer simulations in teacher education. Journal of Educational Technology Systems, 43(1), 3-12.

Braun, V., \& Clarke, V. (2006). Using thematic analysis in psychology. Qualitative Research in Psychology, 3(2), 77-101.

Badiee, F., \& Kaufman, D. (2014). Effectiveness of an online simulation for teacher education. Journal of Technology and Teacher Education, 22(2), 167-186.

Badiee, F., \& Kaufman, D. (2015). Design evaluation of a simulation for teacher education. Sage Open, 5(2). https://doi.org/10.1177/2158244015592454.

Burdea, G. C., \& Coiffet, P. (2003). Virtual reality technology. Wiley.

Cheong, D. (2010). The effects of practice teaching sessions in second life on the change in pre-service teachers' teaching efficacy. Computers \& Education, 55(2), 868-880.

Clapper, T. C. (2010). Role play and simulation. The Education Digest, 75(8), 39-43.

Clark, C. M., \& Peterson, P. L. (1986). Teachers' thought processes. In M. C. Wittrock (Ed.), Handbook of research on teaching (3rd ed.) (pp. 255-296). New York: Macmillan.

Colella, V. (2000). Participatory simulations: Building collaborative understanding through immersive dynamic modeling. The Journal of the Learning Sciences, 9(4), 471-500.

Dalgarno, B., Gregory, S., Knox, V., \& Reiners, T. (2016). Practising teaching using virtual classroom role plays. Australian Journal of Teacher Education (online), 41(1), 126-154.

Dawson, M. R., \& Lignugaris, K. B. (2017). Meaningful practice: Generalizing foundation teaching skills from TLE TeachLivETM to the classroom. Teacher Education and Special Education, 40(1), 26-50.

Deale, D., \& Pastore, R. (2014). Evaluation of simSchool: An instructional simulation for pre-service teachers. Computers in the Schools, 31(3), 197-219.

DeChenne, S. E., Enochs, L. G., \& Needham, M. (2012). Science, technology, engineering, and mathematics graduate teaching assistants teaching self-efficacy. Journal of the Scholarship of Teaching and Learning, 12(4), 102-123.

DeChenne, S. E., Koziol, N., Needham, M., \& Enochs, L. (2015). Modeling sources of teaching selfefficacy for science, technology, engineering, and mathematics graduate teaching assistants. $C B E$ : Life Sciences Education, 14(3), 32. https://doi.org/10.1187/cbe.14-09-0153

Dieker, L. A., Rodriguez, J. A., Lignugaris, K., Hynes, M. C., \& Hughes, C. E. (2014). The potential of simulated environments in teacher education: Current and future possibilities. Teacher Education and Special Education, 37(1), 21-33.

Feldon, D. F., Peugh, J., Timmerman, B. E., Maher, M. A., Hurst, M., Strickland, D., Gilmore, J. A., \& Stiegelmeyer, C. (2011). Graduate students' teaching experiences improve their methodological research skills. Science, 333(6045), 1037-1039.

Ferry, B., Kervin, L., \& Carrington, L. (2012). ClassSim: An Approach to Educator Development Through a Simulation. In Virtual Learning Environments: Concepts, Methodologies, Tools and Applications (pp. 591-605). Hershey, PA:IGI Global.

Frasson, C., \& Blanchard, E. G. (2012). Simulation-based learning. In Encyclopedia of the Sciences of Learning (pp. 3076-3080). Boston: Springer.

Goodyear, P., Carvalho, L., and Dohn, N.B. (2016). Artefacts and activities in the analysis of learning networks. In Research, boundaries, and policy in networked learning (pp. 93-110). Cham, Switzerland: Springer. https://doi.org/10.1007/978-3-319-31130-2_6

Gregory, S., \& Masters, Y. (2012). Real thinking with virtual hats: A role-playing activity for pre-service teachers in Second Life. Australasian Journal of Educational Technology, 28, 3.

Grossman, P., Hammerness, K., \& McDonald, M. (2009). Redefining teaching, re-imagining teacher education. Teachers and Teaching: Theory and Practice, 15(2), 273-289.

Hall, T. J., \& Smith, M. A. (2006). Teacher planning, instruction and refl ection: what we know about teacher cognitive processes. Quest, 58(4), 424-442.

Hummel, H., Geerts, W., Slootmaker, A., Kuipers, D., \& Westera, W. (2015). Collaboration scripts for mastership skills: Online game about classroom dilemmas in teacher education. Interactive Learning Environments, 23(6), 670-682.

Jamaludin, A., Chee, Y. S., \& Ho, C. M. L. (2009). Fostering argumentative knowledge construction through enactive role-play in Second Life. Computers \& Education, 53(2), 317-329. 
Jarmon, L., Traphagan, T., Mayrath, M., \& Trivedi, A. (2009). Virtual world teaching, experiential learning, and assessment: An interdisciplinary communication course in Second Life. Computers \& Education, 53(1), 169-182.

Kane, T., Kerr, K., \& Pianta, R. (2014). Designing teacher evaluation systems: New guidance from the measures of effective teaching project. Wiley.

Kaufman, D., \& Ireland, A. (2016). Enhancing teacher education with simulations. TechTrends, 60(3), 260-267.

Ke, F., Lee, S., \& Xu, X. (2016). Teaching training in a mixed-reality integrated learning environment. Computers in Human Behavior, 62, 212-220.

Ke, F., Pachman, M., \& Dai, Z. (2020). Investigating educational affordances of virtual reality for simulation-based teaching training with graduate teaching assistants. Journal of Computing in Higher Education, 32, 607-627.

Klassen, R. M., \& Tze, V. M. (2014). Teachers' self-efficacy, personality, and teaching effectiveness: A meta-analysis. Educational Research Review, 12, 59-76.

Koc, M. (2011). Let's make a movie: Investigating pre-service teachers' reflections on using videorecorded role playing cases in Turkey. Teaching and Teacher Education, 27(1), 95-106.

Komarraju, M. (2008). A social-cognitive approach to training teaching assistants. Teaching of Psychology, 35(4), 327-334.

Labaree, D. F. (2000). On the nature of teaching and teacher education: Difficult practices that look easy. Journal of Teacher Education, 51(3), 228-233.

Leaman, L. H., \& Flanagan, T. M. (2013). Authentic role-playing as situated learning: Reframing teacher education methodology for higher-order thinking. Studying Teacher Education, 9(1), 45-61.

Mahon, J., Bryant, B., Brown, B., \& Kim, M. (2010). Using second life to enhance classroom management practice in teacher education. Educational Media International, 47(2), 121-134.

Mason, L. L., Jeon, T., Blair, P., \& Glomb, N. (2011). Virtual tutor training: Learning to teach in a multi-user virtual environment. International Journal of Gaming and Computer-Mediated Simulations, 3(1), 51-67.

Mezirow, J. (2000). Learning as Transformation: Critical Perspectives on a Theory in Progress. JosseyBass Publishers.

Mills, N. (2011). Teaching assistants' self-efficacy in teaching literature: Sources, personal assessments, and consequences. The Modern Language Journal, 95(1), 61-80.

Mirliss, D. S. (2014). Preparing future teachers for inclusion classrooms using virtual world role-play activities [Doctoral dissertation]. Teachers College, Columbia University.

Quintana, M. G. B., \& Fernández, S. M. (2015). A pedagogical model to develop teaching skills. The collaborative learning experience in the Immersive Virtual World TYMMI. Computers in Human Behavior, 51, 594-603.

Richards-Babb, M., Penn, J. H., \& Withers, M. (2014). Results of a practicum offering teaching-focused graduate student professional development. Journal of Chemical Education, 91(11), 1867-1873.

Rodriguez, V. (2012). The teaching brain and the end of the empty vessel. Mind, Brain, and Education, 6 , 177-185.

Schunk, D. H., \& Pajares, F. (2009). Self-efficacy theory. In K. R. Wentzel \& A. Wigfield (Eds.), Handbook of motivation at school (pp. 35-52). New York: Routledge.

Shaeffer, S. (1993). Participatory approaches to teacher training. In J. P. Farrell \& J. B. Oliveira (Eds.), Teachers in developing countries: Improving effectiveness and managing costs (pp. 187-200). Washington, D. C.: The World Bank.

Shernoff, E. S., Von Schalscha, K., Gabbard, J. L., Delmarre, A., Frazier, S. L., Buche, C., \& Lisetti, C. (2020). Evaluating the usability and instructional design quality of Interactive Virtual Training for Teachers (IVT-T). Educational Technology Research \& Development. https://doi.org/10.1007/ s11423-020-09819-9

Strauss, S., Ziv, M., \& Stein, A. (2002). Teaching as a natural cognition and its relations to preschoolers' developing theory of mind. Cognitive Development, 17(3-4), 1473-1487.

Suresh, K. P. (2011). An overview of randomization techniques: An unbiased assessment of outcome in clinical research. Journal of Human Reproductive Sciences, 4(1), 8-11.

Theelen, H., Van den Beemt, A., \& den Brok, P. (2019). Classroom simulations in teacher education to support preservice teachers' interpersonal competence: A systematic literature review. Computers \& Education, 129, 14-26.

Tschannen-Moran, M., \& Johnson, D. (2011). Exploring literacy teachers' self-efficacy beliefs: Potential sources at play. Teaching and Teacher Education, 27(4), 751-761. 
Warhurst, R. P. (2006). "We really felt part of something": Participatory learning among peers within a university teaching-development community of practice. International Journal for Academic Development, 11(2), 111-122.

Zee, M., \& Koomen, H. M. (2016). Teacher self-efficacy and its effects on classroom processes, student academic adjustment, and teacher well-being: A synthesis of 40 years of research. Review of Educational Research, 86(4), 981-1015.

Publisher's Note Springer Nature remains neutral with regard to jurisdictional claims in published maps and institutional affiliations. 